\title{
Comparison of single and modular ANN based fault detector and classifier for double circuit transmission lines
}

\author{
Anamika Yadav \\ Department of Electrical Engineering, National Institute of Technology Raipur, INDIA \\ Corresponding Author: e-mail: anamikajugnu4@gmail.com,Tel+91-9425852654
}

\begin{abstract}
Comparison of single and modular artificial neural network based techniques for shunt faults detection and classification in double end fed double circuit transmission line is presented in this paper. The proposed method uses the voltages and currents signals available at the local end of line. The model of the power system is developed using MATLAB® software. Effects of variations in pre-fault power flow angle, fault inception angle, source strength, fault resistance, fault type, fault distance and CT saturation have been investigated extensively on the performance of the ANN based protection scheme. Additionally, the effects of network changes: double circuit and single circuit operation with other line switched out and grounded (/ungrounded), intercircuit and cross-country faults have also been investigated. Thus, the present work encompasses practically the entire range of possible operating conditions, which has not been reported earlier. The simulation results are presented to validate the effectiveness of the proposed approach. The main advantage of the proposed technique is that the variation in power system parameters under a variety of operating conditions and single/double circuit operations does not affect its performance. And this technique correctly detects and classifies the intercircuit and cross-country faults which have not been reported so-far.
\end{abstract}

Keywords: Artificial neural network, cross country fault; transmission line protection; intercircuit faults and single circuit operation.

DOI: http://dx.doi.org/10.4314/ijest.v4i2.9

\section{Introduction}

Double circuit transmission lines are the vital links in power systems evacuating bulk power from generating stations and transmitting it to load centers. They also serve as links between power systems for interchange of energy. Double circuit transmission lines enhance power transfer capacity and reliability. Being exposed to vagaries of atmosphere they are more prone to faults due to external conditions. Faults on transmission lines must be detected correctly and quickly to prevent the disturbance or damage to system and maintain security and reliability of supply.

Protection of double circuit transmission lines pose additional problems due to zero sequence mutual coupling between faulted and healthy circuits during earth faults (Agrasar et al., 1998). The nature of mutual coupling is highly variable; and it is affected by network changes such as switching in/out of one of the parallel lines, thus causing under reach/over reach of conventional distance relaying. The conductor geometry in double circuit lines makes them prone to multi-circuit faults, of which the earthed crosscountry fault is the most common. Nevertheless, unearthed inter-circuit faults create unusual problems for the protection engineers due to the under-reach and the zero-sequence currents present in the circuits themselves (Jongepier and van der Sluis, 1994). These currents do not extend beyond the bus-bars and, consequently, the terminal zero-sequence source impedances have little impact (Spoor and Zhu, 2005). Such faults have a significantly high probability of occurrence as a result of bushfire activity, conductor galloping, or broken conductors on a particular circuit. The under-reach is created by the apparent transition between a doublephase-to-earth to a single-phase fault as the fault location is varied along the circuits. 
Artificial neural network has emerged as a relaying tool for protection of power system equipments (Vankayala and Rao, 1993). ANN has pattern recognition, classification, generalization and fault tolerance capability. ANN has been widely used for developing protective relaying schemes for transmission lines protection. Most of the research on ANN based protection schemes, has been carried out for single circuit transmission lines (Khaparde et al., 1996; Coury and Jorge, 1998; Sanaye-Pasand and Malik, 1998; Mazon et al., 2000; Venkatesan and Balamurugan, 2001; Dash et al., 2001; Lin et al., 2001; Sanaye-Pasand and KhorashadiZadeh, 2003, 2006; Mahanty and Gupta, 2004; Bouthiba, 2004; Samantaray et al., 2006; Xuan et al., 1996; Wang and Keerthipala, 1998). Other techniques such as wavelet, SVM, decision tree based technique, neuro-fuzzy techniques have also been applied to single circuit transmission lines (Reddy and Mohanta, 2007; Salat and Osowski, 2004; Samantaray and Dash, 2008; Samantaray, 2009; Kamel and Moustafa-Hassan, 2010). An adaptive distance protection of double circuit line using zero sequence thevenin equivalent impedance and compensation factor for mutual coupling to increase the reach and selectivity of relay has been developed in Jongepier and van der Sluis (1994). It estimates the fault distance but does not classify the fault. Fault classification using ANN for one circuit of parallel double circuit line has been reported in Dalstain and Kulicke (1995). An ANN based protection technique for combined $275 \mathrm{kV} / 400 \mathrm{kV}$ double circuit transmission lines has been proposed in Xuan, et al. (1998). The fundamental components of voltages and currents are used as input to neural network for a particular type of fault (Single Line to Ground) distance location and zone of fault estimation. A novel fault classification technique of double circuit lines based on a combined unsupervised/supervised neural network has been presented in Agarwal et al. (1999). It considers only A1G, B2G, A1B1G and A1C2 faults and other types of faults have not been considered. Cascade correlation algorithm based ANN is used for fault location and fault resistance determination; but it does not classify the faults (Purushothama et al., 2001). Kohonen network is used to improve the accuracy of distance relay for single line to ground fault on a single line of double circuit lines (Skok et al., 2002.); faults on circuit-2 line have been not considered and it does not classify the faults. The Clarke Concordia transformation, eigen value approach and $\mathrm{NN}$ is used to locate the fault of double circuit line; but it does not identify the faulted phase (Martins et al., 2005).

Adaptive distance relaying scheme for high resistance faults on two terminal parallel transmission lines using radial basis functions neural network has been reported (Bhalja and Maheswari, 2007.). It uses changes in active and reactive power flow and resistance as input to RBFNN and reactance is the output. Only single line to ground faults was considered in this work. In general various techniques reported earlier (Dalstain and Kulicke, 1995; Xuan et al., 1998; Agarwal et al., 1999; Purushothama et al., 2001; Skok et al., 2002; Martins et al., 2005; Bhalja and Maheswari, 2007) for protection of double circuit lines have not considered the inter-circuit or cross-country faults. Transmission lines distance protection using artificial neural networks for single circuit transmission line having any configuration or voltage level in Caneloi dos Santos and Senger (2011). A survey of recent techniques used in transmission line protection has been reported in Babu et al. (2011). Protection of Transmission Lines has been described using Rosenblatt's algorithm of artificial neural network in Awasthi and Ahmed (2012). In Warlyani et al. (2011), fault classification and faulty section identification in teed transmission circuits using ANN has been reported. Further protection of six phase transmission line against Six Phase to Ground Fault using ANN has been presented in Koley et al. (2012).

The work presented in this paper deals with protection of double circuit transmission lines using artificial neural network. Throughout the study a $220 \mathrm{kV}$ double end fed double circuit transmission line of $100 \mathrm{~km}$ length has been chosen as a representative system for fault detection and classification. The work reports the results of extensive "offline" studies using the MATLAB ${ }^{\circledR}$ and its associated toolboxes: Simulink, SimPowerSystems and Neural Network Toolbox. The ANN based protection scheme have been developed for double circuit transmission line using fundamental components of three phase voltages and currents in each circuit. The following two ANN architectures were explored for this task:-

(i) Single ANN for all 10 types of faults

(ii) Modular ANN's for each type of faults (Four ANN modules)

All the 10 types of shunt faults have been investigated with variation in power system parameters; viz. pre-fault power flow angle $\left(\delta_{\mathrm{s}}\right.$ export/import), fault inception angle $\left(\Phi_{\mathrm{i}}\right)$, source strengths at either end $(\mathrm{GVA})$ and its $\mathrm{X} / \mathrm{R}$ ratio, fault resistance $\left(\mathrm{R}_{\mathrm{f}}\right.$ in ohms), and distance to fault $\left(\mathrm{L}_{\mathrm{f}}\right.$ in $\left.\mathrm{km}\right)$. Additionally, the effects of network changes, e.g. double circuit operation and single circuit operation with other circuit switched out and grounded (/ungrounded) at both ends, inter-circuit faults and cross-country faults have also been considered. This encompasses practically the entire range of possible operating conditions and faults which have not been reported in previous works, which is the clear advantage of the proposed technique over other reported works.

\section{Double circuit transmission line network modelling and simulation}

A $220 \mathrm{kV}$ double circuit transmission line fed from sources at each end is simulated using MATLAB ${ }^{\circledR} /$ Simulink and SimPowerSystem toolbox. The Power system model simulated is shown in Fig. 1. The internal impedance of two sources on two sides of the line at SS-1 end and SS-2 end is $45 \angle 82^{\circ}$ and $79.5 \angle 85^{\circ}$ respectively. The transmission line parameters has been obtained through MATLAB software tool "power lineparam" which compute RLC parameters of overhead transmission line from its conductor characteristics and tower geometry. Double circuit transmission line parameters are given in Table 1 . The effect of mutual coupling between the two circuits and various types of faults with different system conditions and parameters are considered. 


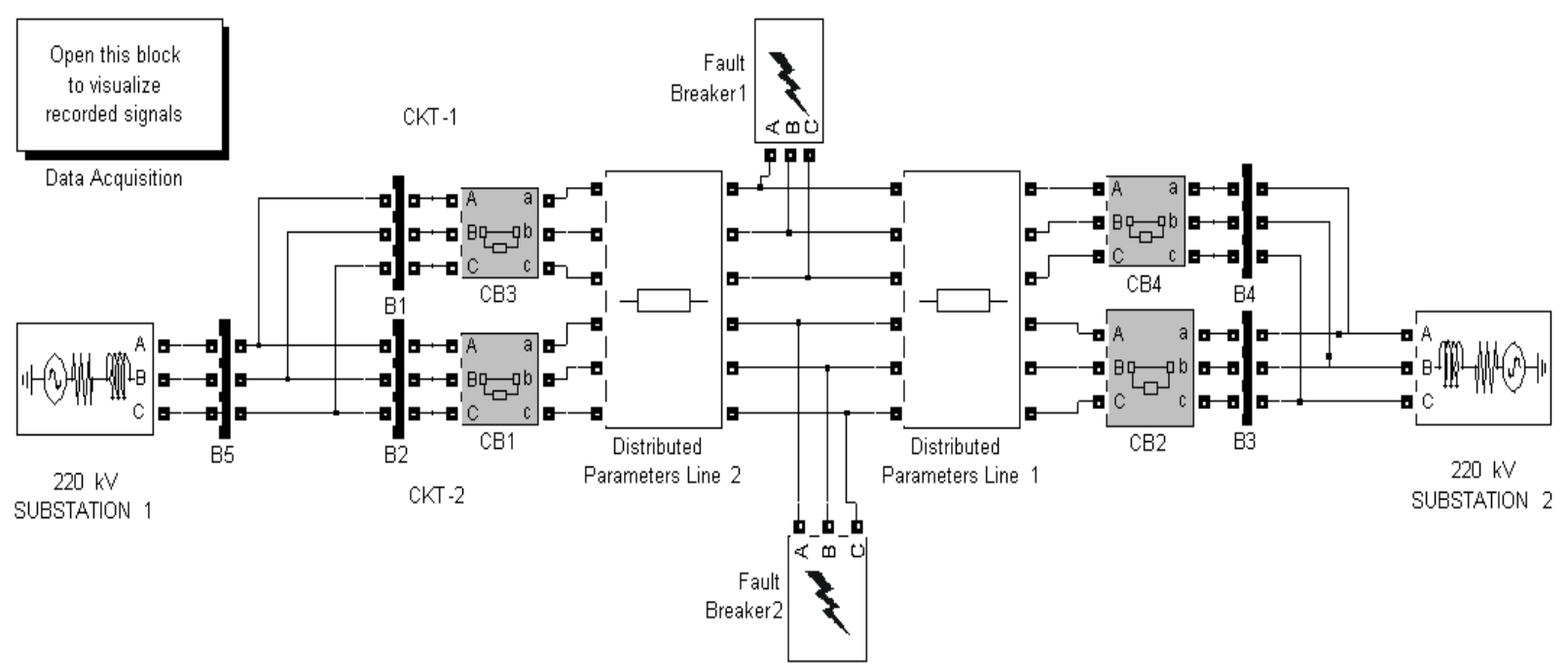

Figure 1. Double circuit transmission line network simulated using MATLAB ${ }^{\circledR}$ software.

Table 1. Double circuit transmission line parameters

\begin{tabular}{|l|l|}
\hline Parameters & Set Value \\
\hline Positive sequence resistance $\mathrm{R} 1, \Omega / \mathrm{km}$ & 0.01809 \\
\hline Zero sequence resistance $\mathrm{R} 0, \Omega / \mathrm{km}$ & 0.2188 \\
\hline Zero sequence mutual resistance $\mathrm{R} 0 \mathrm{~m}, \Omega / \mathrm{km}$ & 0.20052 \\
\hline Positive sequence inductance $\mathrm{L} 1, \mathrm{H} / \mathrm{km}$ & 0.00092974 \\
\hline Zero sequence inductance $\mathrm{L} 0, \mathrm{H} / \mathrm{km}$ & 0.0032829 \\
\hline Zero sequence mutual inductance $\mathrm{L} 0 \mathrm{~m}, \mathrm{H} / \mathrm{km}$ & 0.0020802 \\
\hline Positive sequence capacitance $\mathrm{C} 1, \mathrm{~F} / \mathrm{km}$ & $1.2571 \mathrm{e}-008$ \\
\hline Zero sequence capacitance $\mathrm{C} 0, \mathrm{~F} / \mathrm{km}$ & $7.8555 \mathrm{e}-009$ \\
\hline Zero sequence mutual capacitance $\mathrm{C} 0 \mathrm{~m}, \mathrm{~F} / \mathrm{km}$ & $-2.0444 \mathrm{e}-009$ \\
\hline
\end{tabular}

\section{Single ANN based fault detection and classification}

A single ANN for fault detection and classification of all the ten type of faults in both the circuit under varying power system operating conditions has been developed. The block diagram of the proposed single ANN based fault detector and classifier approach is shown in Fig. 2.

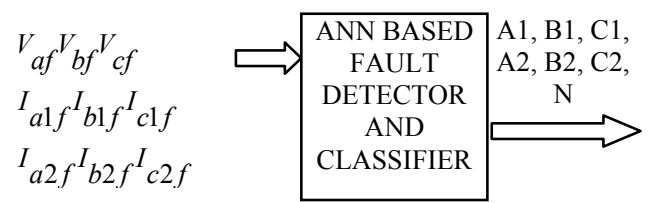

Figure 2. Block diagram of Single ANN based fault detector and classifier.

3.1 ANN inputs and Outputs: The ANN inputs chosen here are the magnitudes of the fundamental components (50 Hz) of three phase voltages and six currents measured at the relay location. Only the magnitudes recorded at one end of the line are used. Thus, the ANN inputs are nine:

$X=\left[V_{a f}, V_{b f}, V_{c f}, I_{a 1 f}, I_{b 1 f}, I_{c 1 f}, I_{a 2 f}, I_{b 2 f}, I_{c 2 f}\right]$

In order to determine the type of fault and identify the faulted phases, six outputs representing each three phase of circuit- 1 and circuit-2 and one output representing neutral/ ground (total seven outputs) have been considered by the network. The output should be 0 or 1 in the corresponding phases and/or in neutral according to the type of fault which occurs on the system. Thus the ANN outputs are seven:

$Y=[A 1, B 1, C 1, A 2, B 2, C 2, N]$

Applying the above input and output data pattern to the ANN for training, it was found that the fault detector and classifier correctly detects and classifies all types of faults in each circuit. 
3.2 Fault Patterns Generation and Preprocessing: The ANN requires sufficient number of fault patterns and no-fault patterns to learn the fundamental characteristics of the problem. Three phase voltages and three phase current signals of both the circuits were sampled at a sampling frequency of $1 \mathrm{kHz}$ and further processed by simple 2nd-order low-pass Butter worth filter. The filter removes the unwanted frequencies from a sampled waveform. If the Nyquist frequency corresponds to a sampling rate of $\mathrm{N}$ times per cycle, it also determines the highest order harmonic frequency in the waveform which can be estimated. Of particular concern is the fundamental phasor, which is used in relay applications. The anti-aliasing filter removes harmonics 8 times above the $50 \mathrm{~Hz}$ frequency to prevent corruption of the desired phasor. Thus the cut-off frequency of filter is $8 \times 50=400 \mathrm{~Hz}$. Then one full cycle Discrete Fourier transform is used to calculate the fundamental component of voltages and currents. It should be mentioned that the input signals have to be normalized in order to reach the ANN input level $( \pm 1)$. The routine 'premnmx' of the neural network toolbox of MATLAB ${ }^{\circledR}$ is used to normalize the input signals.

One full cycle Discrete Fourier transform is used to calculate the fundamental component of voltages and currents. The process of estimation of fundamental component of voltages and currents is continuous for complete simulation time of 0.2 sec. The sampling frequency is $1 \mathrm{kHz}$; we get 20 samples in one cycle and overall 200 samples in $0.2 \mathrm{sec}$. For training of ANN, the post fault samples of fundamental component of voltages and currents has been extracted using half cycle moving window length as the fault is occurring at different instants i.e. 10 samples have been extracted for a particular type of fault. Say for examples if fault has occurred at $60 \mathrm{~ms}$ then, 10 post fault samples have been extracted for this case i.e. 10 samples indicate half cycle data. The extraction of fault samples involves moving data window of half cycle length as fault inception time is varying i.e. 10 number of post fault samples have been extracted from each fault simulation. Using SIMULINK \& SIMPOWERSYSTEM toolbox of MATLAB ${ }^{\circledR}$ all the ten type of faults at different fault locations between $0-100 \%$ of line length and fault inception angles 0 \& $90^{\circ}$ have been simulated as shown in Table 2.

The total number of ground faults simulated are $=12(3 \mathrm{LG}+3 \mathrm{LLG}$ in ckt- 1 and ckt-2 each)*10 (no. of fault locations $1,10,20$, $30, \ldots 80$ and $90 \mathrm{~km}$ )*2 (Fault inception angle $\left.0^{\circ} \& 90^{\circ}\right) * 3($ Fault resistance $0,50 \& 100 \Omega$ ) $=720$

Total no. of phase faults are $=8(3 \mathrm{LL}+1 \mathrm{LLL}$ in ckt- 1 and ckt- 2 each) $* 10($ no. of fault locations $1,10,20,30, \ldots 80$ and $90 \mathrm{~km}) * 2$ (Fault inception angle $\left.0^{\circ} \& 90^{\circ}\right)=160$

Thus total fault cases are $720+160=880$ and from each fault cases; 10 number of post fault samples have been extracted, also 35 no-fault samples are taken to form the training data set for ANN. Thus; the total number of patterns generated for training is 4435 . Training matrices were built in such a way that the network trained produces an output corresponding to the type of fault.

Table 2. Training patterns generation for single ANN based fault detector and classifier

\begin{tabular}{|l|l|}
\hline Parameter & Set value \\
\hline & LG: A1N, A2N, B1N, B2N, C1N, C2N \\
& LL: A1B1, A2B2, B1C1, B2C2, A1C1, A2C2 \\
& LLG: A1B1N, A2B2N, B1C1N, B2C2N, \\
& A1C1N, A2C2N \\
& LLL: A1B1C1, A2B2C2 \\
\hline Fault type & $1,10,20,30, \ldots 80$ and $90 \mathrm{~km}$ \\
\hline Fault inception angle $\left(\Phi_{\mathrm{i}}\right)$ & $0^{\circ} \& 90^{\circ}$ \\
\hline Fault resistance $\left(\mathrm{R}_{\mathrm{f}}\right)$ & $0,50 \& 100 \Omega$ \\
\hline Pre-fault power flow angle $\left(\delta_{\mathrm{s}}\right)$ & $45^{\circ}$ \\
\hline
\end{tabular}

3.3 Training Process: The proposed methodology of fault detection and classification using ANN is depicted in Fig. 3. Once the network input and outputs have been selected, the final determination of the ANN architecture requires the relevant transfer functions in the hidden and output layers to be established. Activation function of the hidden layer is hyperbolic tangent sigmoid function. Neurons with sigmoid function produce real valued outputs that give the ANN ability to construct complicated decision boundaries in an n-dimensional feature space (Haykin, 2003.). This is important because the smoothness of the generalization function produced by the neurons, and hence its classification ability, is directly dependent on the nature of the decision boundaries. Saturating linear transfer function (Satlin) has been used in the output layer as shown in Fig.4, as output should be 0 or 1 based on the fault type which occurs on the system. The single ANN based fault detector \& classifier was trained using Levenberg-Marquardt training algorithm as it gives fastest convergence as compared with other algorithms (Hagan and Menhaj, 1994.). To decide the no. of neurons in the hidden layer, there is currently no mathematical theory. The reality is that structured trial and error must be used. If too few hidden neurons are used, the network will be unable to model complex data, resulting in a poor fit. If too many hidden neurons are used, then training will become excessively long and the network may over fit. The structured trial and error process generally used to determine the number of hidden neurons relies on the premise that networks with too many hidden neurons will converge. Therefore, the goal is try to quickly find the smallest network that converges and then refine the answer by working back from there. 
- Start with one hidden neuron - the equivalent of a single layer Perceptron.

- Begin training the network.

- If the network fails to converge after a reasonable period, restart training up to ten times, thus ensuring that it has not fallen into a local minimum.

- If the network still fails to converge, add another hidden neuron and return to step two.

- If you get to here, then the network has converged.

The Numbers of hidden layer neuron for single ANN are chosen initially to 5 and then increased in step to $10,20,30,40$ to 50 as described above. The final performance error goal has been converged with 50 neurons. In this learning strategy, the mean square error (mse) decreases in 150 epochs to 3.60926 e-04 in around two and half hours learning time on a PC (P4, 2.66GHz, 1GB RAM). The training of single ANN based fault detector \& classifier takes long time and also the memory requirement is high for singular ANN while training process, if the memory of the PC used is not large then the training cannot be performed because of error while training in MATLAB software "out of memory error". However during testing phase it is almost instantaneous.

Simulate all ten types of faults in both the circuit of the double circuit transmission line using Matlab software

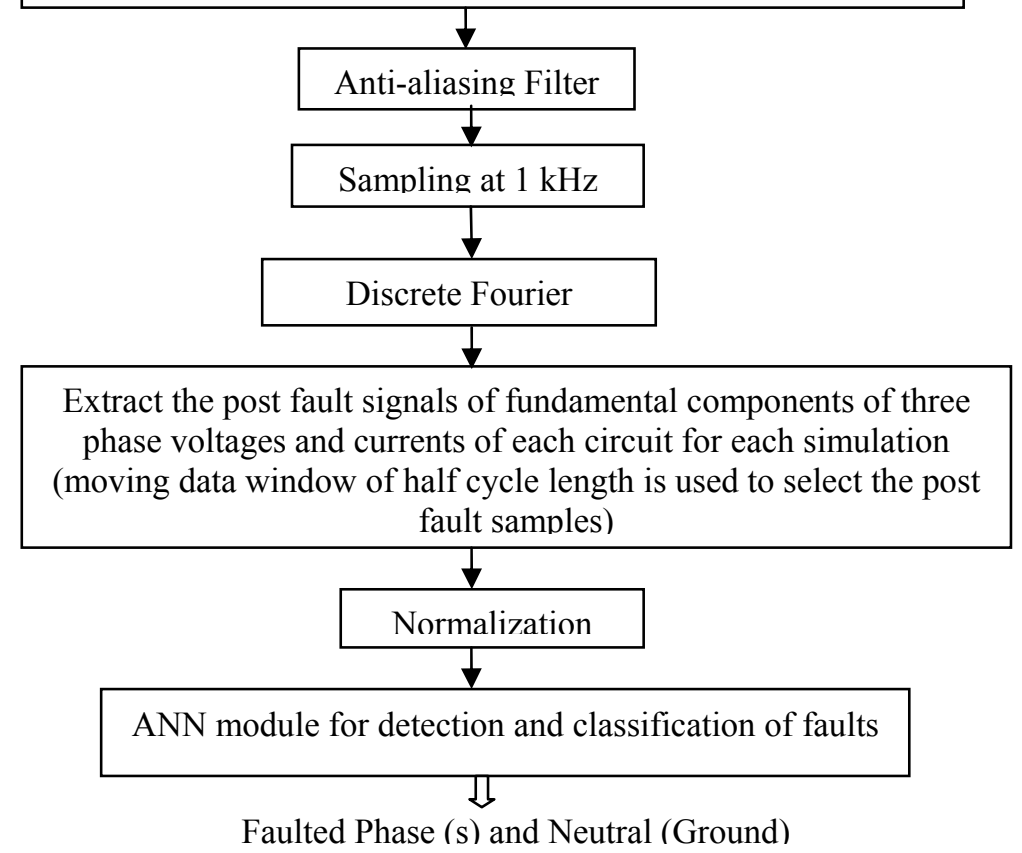

Figure 3. Proposed methodology of ANN based fault detection and classification.

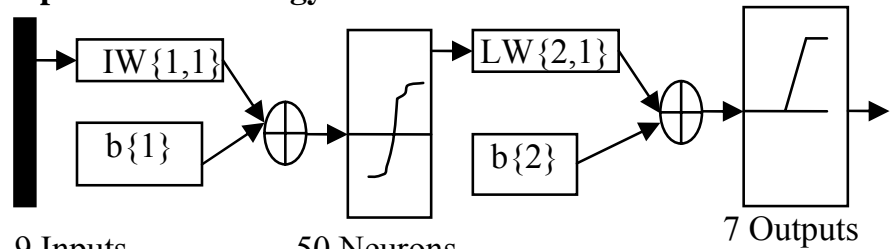

9 Inputs

50 Neurons

Figure 4. Architecture of single ANN based fault detector and classifier.

\section{Modular Artificial Neural Network Based Fault Detection and Classification}

Single architecture of ANN for all ten types of fault involves complexity, less accuracy, large training sets and time, slow learning capability and larger errors. In order to have more accuracy and correctness in the detection and classification, it was decided to develop a modular neural network for each type of faults. In this approach any task is divided into number of possible subtasks where each one is accomplished by an individual neural network. Finally, all network outputs are integrated to achieve the overall task. Obviously the approach has the advantages of simplicity, higher accuracy, less training sets and training time, easier interpretation, model complexity reduction and better learning capability. Thus the memory requirement of modular network is not large. In modular network the training data is reduced according to the type of fault, thus it does not require large memory during training process.

Four different ANN modules were developed to process different fault type, i.e. phase to ground faults, double phase to ground faults, phase to phase faults and three phase faults. Based on the fault type, appropriate network detects and classifies the fault. Further refer to Table-3, different architectures are there as the training of modular networks involves different fault patterns according to their fault type (LG, LL, LLG, LLL). The inputs and outputs of modular ANN based fault detector and classifier are the same as used for single ANN based fault detector and classifier approach i.e. total nine inputs and seven outputs. The block 
diagram of the proposed modular ANN based fault detector and classifier approach is shown in Fig. 5. The procedure for development of the architecture of modular ANN based fault detector and classifier is same as that of single ANN based fault detector and classifier. The final architecture of modular ANN based fault detector and classifier is shown in Table 3. The training time is very less for modular networks approximately 15 minutes for all four modules.

Table 3. Architecture of modular ANN based fault detector and classifier

\begin{tabular}{|l|l|l|l|}
\hline S.NO. & $\begin{array}{l}\text { ANN BASED FAULT } \\
\text { DETECTOR \& CLASSIFIER } \\
\text { TYPE }\end{array}$ & ARCHITECTURE & $\begin{array}{c}\text { MEAN SQUARE } \\
\text { ERROR (MSE) }\end{array}$ \\
\hline 1. & Phase to ground fault NN & $9-30-7$ & $5.70417 \mathrm{e}-04$ \\
\hline 2. & Phase to phase fault NN & $9-30-7$ & $1.88598 \mathrm{e}-05$ \\
\hline 3. & Double phase to ground fault NN & $9-8-7$ & $3.13943 . \mathrm{e}-06$ \\
\hline 4. & Three phase fault NN & $9-20-7$ & $3.13362 \mathrm{e}-006$ \\
\hline
\end{tabular}

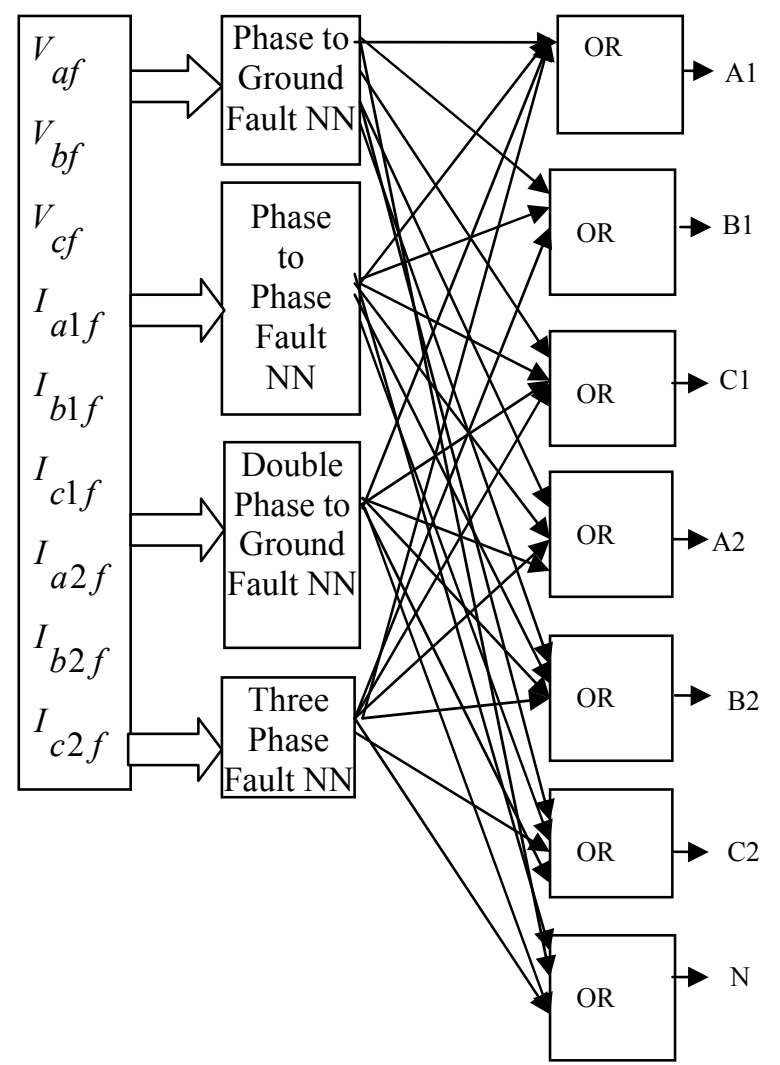

Figure 5. Block diagram of modular ANN based fault detector and classifier.

\section{Comparison of Test Results of Single and Modular ANN Based Fault Detector and Classifier}

After training, single and modular ANN based fault detector and classifier were extensively tested using independent data sets consisting of fault samples never used previously in training. The network was tested by presenting 240 different types of faults with varying fault locations $\left(\mathrm{L}_{\mathrm{f}}=0-95 \mathrm{~km}\right)$, fault inception angles $\left(\Phi_{\mathrm{i}}=0-360^{\circ}\right)$ and fault resistance $\left(\mathrm{R}_{\mathrm{f}}=0-100 \Omega\right)$. During training total number of fault patterns used were 8800. Further to evaluate the performance of the trained ANN based detector and classifier, 10 number of post fault samples were extracted each from 240 different types of faults cases forming around 2400 fault patterns which have been used during testing phase. The percentage of successful fault detection and classification is $98 \%$ and percentage of misclassification/failure is $2 \%$. Some of the test results of the proposed ANN based fault detector and classifier under single line to ground faults with different power system conditions are presented in Table 4. For example test result during A1N fault occurring in circuit- 1 at $L_{f}=45 \mathrm{~km}, \Phi_{\mathrm{i}}=90^{\circ}$ and $R f=90 \Omega$ is shown in table 4 first row. The phase $A 1$ and $N$ outputs of ANN is high exactly one (1) and all other outputs $B 1, C 1, A 2, B 2, \mathrm{C} 2$ are low exactly zero (0) because the transfer function used in output layer of ANN is saturating linear. The "satlin" transfer function enables to get the exact outputs either 0 or 1 . Further some of the test results for individual types of fault under varying fault parameters are described in the following sub-sections. 
Table 4. Test results of ANN based fault detector \& classifier

\begin{tabular}{|c|c|c|c|c|c|c|c|c|c|c|}
\hline \multirow{2}{*}{$\begin{array}{l}\text { Fault } \\
\text { type }\end{array}$} & \multirow{2}{*}{$\begin{array}{c}\text { Fault } \\
\text { Inception } \\
\text { angle } \Phi_{\mathrm{i}}\left({ }^{\circ}\right)\end{array}$} & \multirow{2}{*}{$\begin{array}{c}\text { Fault } \\
\text { Resistance } \\
\boldsymbol{R}_{f}(\Omega)\end{array}$} & \multirow{2}{*}{$\begin{array}{c}\text { Fault } \\
\text { Location } \\
L_{f}(\mathbf{k m})\end{array}$} & \multicolumn{7}{|c|}{$\begin{array}{c}\text { ANN based fault detector and } \\
\text { classifier output }\end{array}$} \\
\hline & & & & $A 1$ & $B 1$ & $C 1$ & $A 2$ & $B 2$ & $C 2$ & $N$ \\
\hline A1N & 90 & 90 & 45 & 1 & 0 & 0 & 0 & 0 & 0 & 1 \\
\hline A1N & 45 & 80 & 67 & 1 & 0 & 0 & 0 & 0 & 0 & 1 \\
\hline $\mathrm{A} 1 \mathrm{~N}$ & 0 & 20 & 88 & 1 & 0 & 0 & 0 & 0 & 0 & 1 \\
\hline A2N & 45 & 60 & 57 & 0 & 0 & 0 & 1 & 0 & 0 & 1 \\
\hline A2N & 90 & 90 & 77 & 0 & 0 & 0 & 1 & 0 & 0 & 1 \\
\hline A2N & 90 & 40 & 84 & 0 & 0 & 0 & 1 & 0 & 0 & 1 \\
\hline B1N & 135 & 0 & 5 & 0 & 1 & 0 & 0 & 0 & 0 & 1 \\
\hline $\mathrm{B} 1 \mathrm{~N}$ & 180 & 70 & 55 & 0 & 1 & 0 & 0 & 0 & 0 & 1 \\
\hline $\mathrm{B} 1 \mathrm{~N}$ & 225 & 90 & 88 & 0 & 1 & 0 & 0 & 0 & 0 & 1 \\
\hline $\mathrm{B} 2 \mathrm{~N}$ & 180 & 90 & 45 & 0 & 0 & 0 & 0 & 1 & 0 & 1 \\
\hline $\mathrm{B} 2 \mathrm{~N}$ & 360 & 90 & 66 & 0 & 0 & 0 & 0 & 1 & 0 & 1 \\
\hline $\mathrm{B} 2 \mathrm{~N}$ & 270 & 80 & 89 & 0 & 0 & 0 & 0 & 1 & 0 & 1 \\
\hline C1N & 0 & 0 & 4 & 0 & 0 & 1 & 0 & 0 & 0 & 1 \\
\hline C1N & 225 & 15 & 58 & 0 & 0 & 1 & 0 & 0 & 0 & 1 \\
\hline C1N & 360 & 95 & 95 & 0 & 0 & 1 & 0 & 0 & 0 & 1 \\
\hline $\mathrm{C} 2 \mathrm{~N}$ & 0 & 100 & 15 & 0 & 0 & 0 & 0 & 0 & 1 & 1 \\
\hline $\mathrm{C} 2 \mathrm{~N}$ & 180 & 70 & 38 & 0 & 0 & 0 & 0 & 0 & 1 & 1 \\
\hline $\mathrm{C} 2 \mathrm{~N}$ & 315 & 88 & 73 & 0 & 0 & 0 & 0 & 0 & 1 & 1 \\
\hline A1B1 & 135 & - & 5 & 1 & 1 & 0 & 0 & 0 & 0 & 0 \\
\hline A1B1 & 270 & - & 83 & 1 & 1 & 0 & 0 & 0 & 0 & 0 \\
\hline A2B2 & 0 & - & 15 & 0 & 0 & 0 & 1 & 1 & 0 & 0 \\
\hline A2B2 & 135 & - & 85 & 0 & 0 & 0 & 1 & 1 & 0 & 0 \\
\hline $\mathrm{B} 1 \mathrm{C} 1$ & 360 & - & 33 & 0 & 1 & 1 & 0 & 0 & 0 & 0 \\
\hline B1C1 & 0 & - & 76 & 0 & 1 & 1 & 0 & 0 & 0 & 0 \\
\hline $\mathrm{B} 2 \mathrm{C} 2$ & 45 & - & 45 & 0 & 0 & 0 & 0 & 1 & 1 & 0 \\
\hline $\mathrm{B} 2 \mathrm{C} 2$ & 135 & - & 90 & 0 & 0 & 0 & 0 & 1 & 1 & 0 \\
\hline C1A1 & 90 & - & 22 & 1 & 0 & 1 & 0 & 0 & 0 & 0 \\
\hline C1A1 & 180 & - & 88 & 1 & 0 & 1 & 0 & 0 & 0 & 0 \\
\hline $\mathrm{C} 2 \mathrm{~A} 2$ & 225 & - & 59 & 0 & 0 & 0 & 1 & 0 & 1 & 0 \\
\hline $\mathrm{C} 2 \mathrm{~A} 2$ & 315 & - & 64 & 0 & 0 & 0 & 1 & 0 & 1 & 0 \\
\hline A1B1N & 0 & 70 & 45 & 1 & 1 & 0 & 0 & 0 & 0 & 1 \\
\hline A1B1N & 135 & 30 & 85 & 1 & 1 & 0 & 0 & 0 & 0 & 1 \\
\hline A2B2N & 45 & 60 & 57 & 0 & 0 & 0 & 1 & 1 & 0 & 1 \\
\hline A2B2N & 90 & 90 & 77 & 0 & 0 & 0 & 1 & 1 & 0 & 1 \\
\hline B1C1N & 0 & 10 & 35 & 0 & 1 & 1 & 0 & 0 & 0 & 1 \\
\hline B1C1N & 225 & 100 & 88 & 0 & 1 & 1 & 0 & 0 & 0 & 1 \\
\hline $\mathrm{B} 2 \mathrm{C} 2 \mathrm{~N}$ & 180 & 50 & 16 & 0 & 0 & 0 & 0 & 1 & 1 & 1 \\
\hline $\mathrm{B} 2 \mathrm{C} 2 \mathrm{~N}$ & 270 & 80 & 89 & 0 & 0 & 0 & 0 & 1 & 1 & 1 \\
\hline C1A1N & 315 & 0 & 4 & 1 & 0 & 1 & 0 & 0 & 0 & 1 \\
\hline C1A1N & 225 & 30 & 58 & 1 & 0 & 1 & 0 & 0 & 0 & 1 \\
\hline $\mathrm{C} 2 \mathrm{~A} 2 \mathrm{~N}$ & 90 & 40 & 24 & 0 & 0 & 0 & 1 & 0 & 1 & 1 \\
\hline C2A2N & 360 & 95 & 63 & 0 & 0 & 0 & 1 & 0 & 1 & 1 \\
\hline $\mathrm{A} 1 \mathrm{~B} 1 \mathrm{C} 1$ & 45 & - & 3 & 1 & 1 & 1 & 0 & 0 & 0 & 0 \\
\hline A1B1C1 & 135 & - & 5 & 1 & 1 & 1 & 0 & 0 & 0 & 0 \\
\hline A1B1C1 & 180 & - & 25 & 1 & 1 & 1 & 0 & 0 & 0 & 0 \\
\hline $\mathrm{A} 1 \mathrm{~B} 1 \mathrm{C} 1$ & 225 & - & 33 & 1 & 1 & 1 & 0 & 0 & 0 & 0 \\
\hline A1B1C1 & 45 & - & 95 & 1 & 1 & 1 & 0 & 0 & 0 & 0 \\
\hline $\mathrm{A} 2 \mathrm{~B} 2 \mathrm{C} 2$ & 315 & - & 1 & 0 & 0 & 0 & 1 & 1 & 1 & 0 \\
\hline $\mathrm{A} 2 \mathrm{~B} 2 \mathrm{C} 2$ & 180 & - & 15 & 0 & 0 & 0 & 1 & 1 & 1 & 0 \\
\hline $\mathrm{A} 2 \mathrm{~B} 2 \mathrm{C} 2$ & 270 & - & 65 & 0 & 0 & 0 & 1 & 1 & 1 & 0 \\
\hline $\mathrm{A} 2 \mathrm{~B} 2 \mathrm{C} 2$ & 360 & - & 85 & 0 & 0 & 0 & 1 & 1 & 1 & 0 \\
\hline
\end{tabular}


5.1 Test Results of phase to phase fault with varying source strengths: Test results of single and modular ANN based fault detector and classifier for a phase to phase fault in circuit- 2 with variation in source strength are shown in Fig. 6(a) and (b) respectively. Test conditions were "A2C2" fault at $18 \mathrm{~km}$ from the source "SS-1". Fault has occurred at $65 \mathrm{~ms}\left(\Phi_{\mathrm{i}}=90^{\circ}\right), \delta_{\mathrm{s}}=45^{\circ}$; source at SS-1 end has strength of $1.25 \mathrm{GVA}$ and its $\mathrm{X}_{\mathrm{s}} / \mathrm{R}_{\mathrm{s}}$ ratio is 10 and source at SS-2 end has strength of $0.25 \mathrm{GVA}$ and its $\mathrm{X}_{\mathrm{s}} / \mathrm{R}_{\mathrm{s}}$ ratio is 5 . It is clear from the Fig. 6 (a) that all the outputs of ANN are low before the occurrence of fault. As soon as the A2C 2 fault occurs at $65 \mathrm{~ms}$, output of ANN becomes high in corresponding phases i.e. A2, C2 and other outputs are low, also neutral " $N$ " output is high for one cycle time after the onset of fault, thereafter it lowers down to zero value. The detection and classification of fault is simultaneous, as before the fault all outputs ore low and after occurrence of fault the corresponding output according to type of fault becomes high. The single ANN based fault detector and classifier misclassifies the phase to phase fault as double phase to ground fault for one cycle time only, thereafter it correctly classifies the fault as phase to phase fault. This is not a serious problem because corresponding phases are correctly detected as faulted phases and it does not lead to maloperation of the relays as the relays are installed in phase not in neutral. Further the problem of misclassification of one cycle time has been removed with the modular ANN based fault detector and classifier. The modular ANN based fault detector and classifier correctly detects and classifies the $A 2 C 2$ " fault in ckt-2 as phase to phase fault in ckt-2 as shown in Fig. 6(b). However the conventional distance relaying scheme mal-operates in this condition.
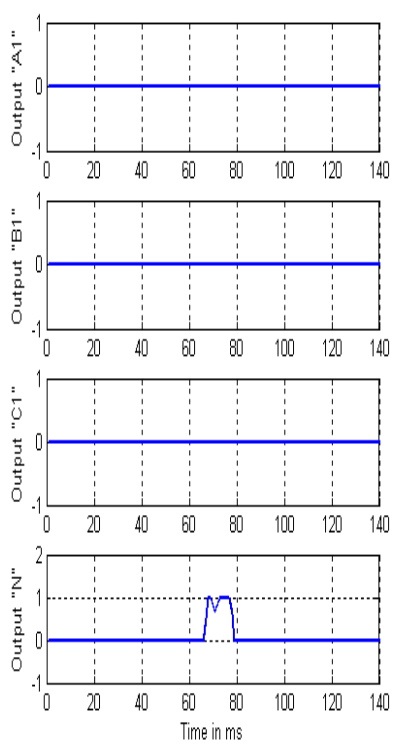

Figure 6. (a)
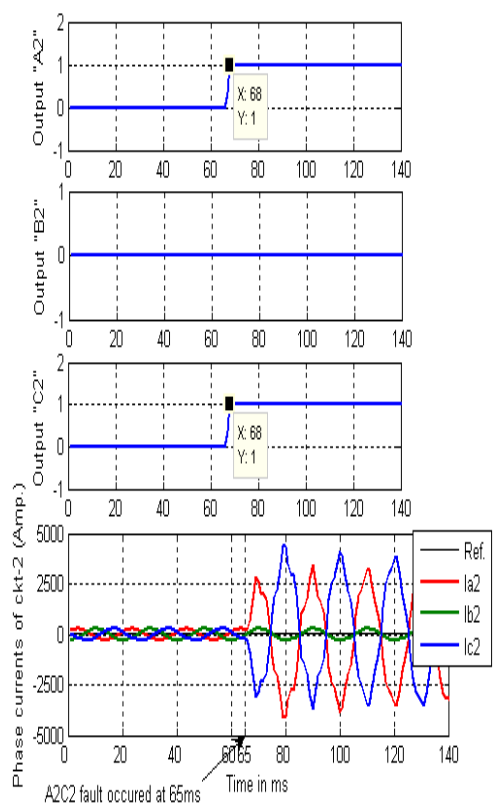
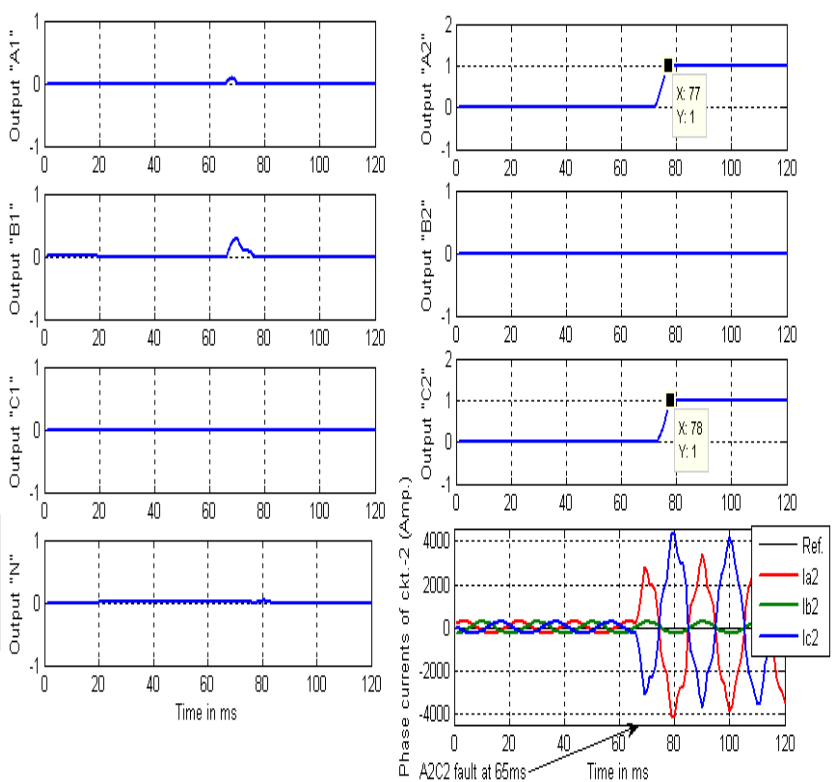

Figure 6. (b)

Figure 6. (a) and (b) Test results of single and modular ANN based fault detector/ classifier during varying source strength on either side respectively.

In Figure 6(a), plot is obtained for output of single ANN based fault detector/ classifier for $A 2 C 2$ " fault in ckt-2 occurred at $65 \mathrm{~ms}$ and it is detected and classified as phase to phase fault after $68 \mathrm{~ms}$ time.

Time of operation $=68-65=3 \mathrm{~ms}$ (less than quarter cycle)

Time of operation in terms of cycles $=3 \mathrm{~ms} / 20 \mathrm{~ms}$

$$
=0.15 \text { cycle. }
$$

In Figure 6(b), plot is obtained for output of modular ANN based fault detector/ classifier for A2C2" fault in ckt-2 occurred at $65 \mathrm{~ms}$ and it is detected and classified as phase to phase fault after $78 \mathrm{~ms}$ time.

Time of operation $=78-65=13 \mathrm{~ms}$ (less than one cycle)

Time of operation in terms of cycles $=13 \mathrm{~ms} / 20 \mathrm{~ms}$

$$
=0.6 \text { cycle. }
$$

The type of fault is correctly detected and classified by modular ANN based fault detector and classifier within one cycle from the inception of fault. The computation of fundamental components by 1 cycle DFT is continuous (i.e. DFT computes the fundamental values of voltages and currents in pre-fault, during fault and post fault conditions). ANN learns to recognize the changes occurring in fundamental values of voltages and currents as soon as the fault occurs and gives output high in the corresponding phases and neutral which are involved in the fault in less than 1 cycle time from the inception of fault. 
5.2 Test Results of cross-country faults: The single and modular ANN based fault detector and classifier were also tested for crosscountry faults. The term cross-country fault is used to describe simultaneous earth faults which occur on different line sections and on different phases of the same circuit. These types of faults are more likely to occur on double circuit lines located on the same tower structures and may result due to bush fires under the lines, lightning, as well as broken conductors. Cross-country faults result in unusual current distributions that compromise the seen impedance by units not directly involved in the fault loop, giving fault selector problems for close-in faults (PDCTL, 2012). Such type of fault cannot be detected by the conventional distance relaying scheme as they cannot estimate the exact distance of cross country fault.

As an example, two different faults were applied at different locations on the transmission line and the test results during crosscountry fault are shown in Fig. 7(a) and (b). For this example the test conditions were: "A1N" fault at $30 \mathrm{~km}$ from SS-1 end at 60 $\mathrm{ms}$ and "B1N" fault at $50 \mathrm{~km}$ at $65 \mathrm{~ms}$ with $\mathrm{Rf}=0 \Omega, \delta \mathrm{s}=45^{\circ}$. This is also known as sequential or evolving fault because at $60 \mathrm{~ms}$ it is single phase to ground fault and then at $65 \mathrm{~ms}$ it has changed to double phase to ground fault. As shown in Fig. 7 (a) and (b), the single and modular ANN based fault detector and classifier detects and classifies the fault correctly within one cycle from the inception of fault.

5.3 Test Results of inter-circuit faults: The un-earthed inter-circuit fault is used to describe short circuits which occur on different phases or same phases of different circuits of line on same location. During non-earthed intercircuit faults, zero sequence current is also present which poses problem (Spoor and Zhu, 2005). Conventional distance relaying scheme is not able to identify the intercircuit fault. The ANN has not been trained with inter-circuit faults patterns. Only the ten types of shunt faults have been used for training of ANN, however the proposed relaying algorithm was tested to check its performance during un-earthed inter-circuit fault also. As an example, short circuit between B1 phase of circuit-1 and $\mathrm{C} 2$ phase of circuit-2 is applied at $10 \mathrm{~km}$ at $60 \mathrm{~ms}$ with $\mathrm{R}_{\mathrm{f}}$ $=0 \Omega, \delta_{\mathrm{s}}=45^{\circ}$.
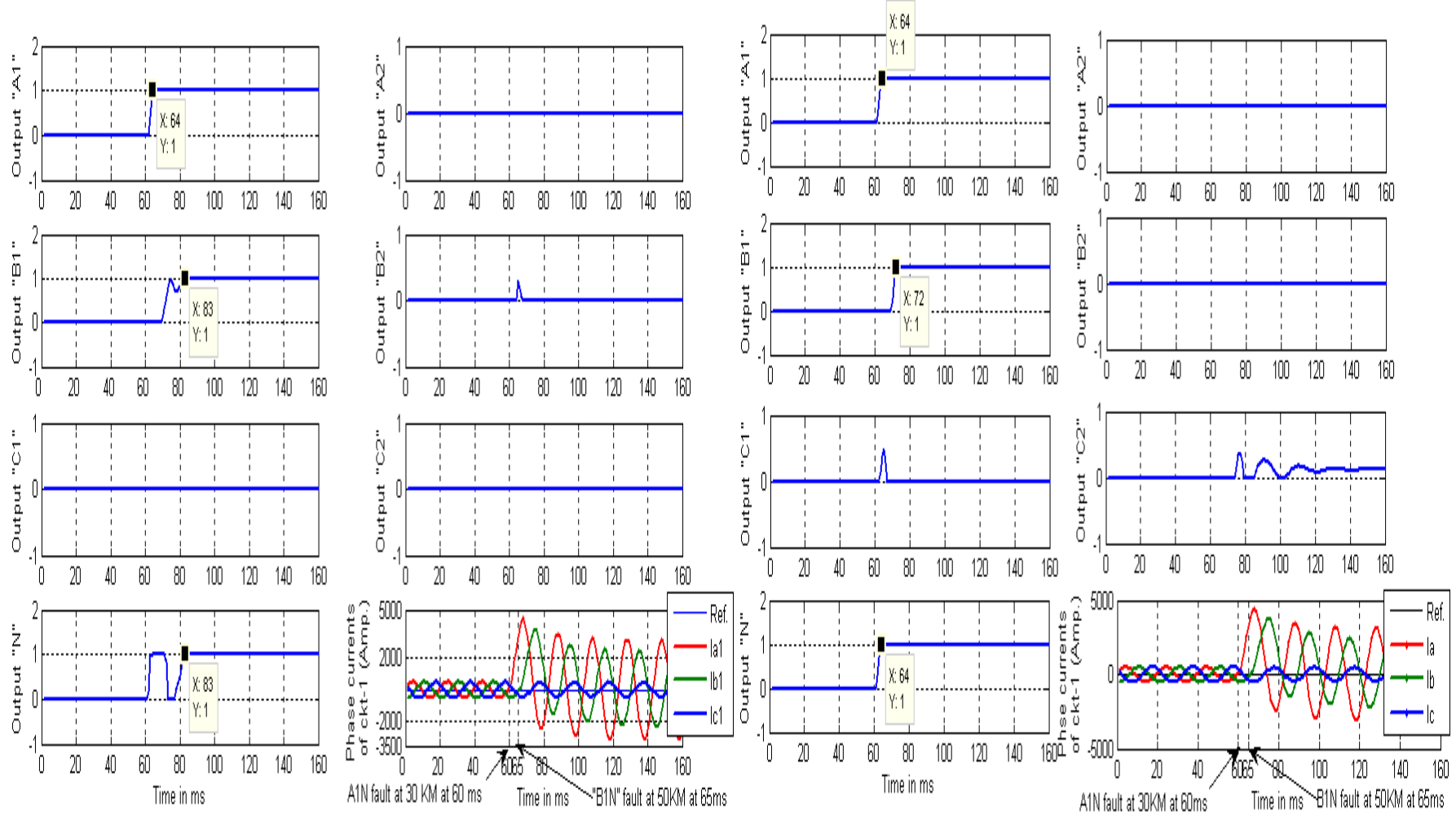

Figure 7. (a)

Figure 7. (b)

Figure 7. (a) and (b) Test results of single and modular ANN based fault detector/ classifier for cross-country fault respectively.

The Fig.8 shows the waveform of zero sequence current present during such condition. The test results of single and modular ANN during un-earthed inter-circuit fault are shown in Fig. 9 (a) and (b). As shown in Fig. 9, the network outputs of corresponding phases B1, C2 are high and other phases outputs are well below the threshold limit 0.3. However, neutral "N" output of single ANN based fault detector has fluctuation whereas it is constantly high in modular ANN based fault detector. The neutral output is also high for $\mathrm{B} 1 \mathrm{C} 2$ fault because of the fact that during non-earthed intercircuit faults, zero sequence current is also present which flows through neutral, and it is detected by ANN and neutral output goes high. Thus, the un-earthed inter-circuit fault is detected and classified within one cycle from the inception of fault by both types of fault detector and classifier. The test results are very 
accurate, which confirms the adaptability and suitability of the proposed ANN for detection and classification of inter-circuit faults under varying fault situations.

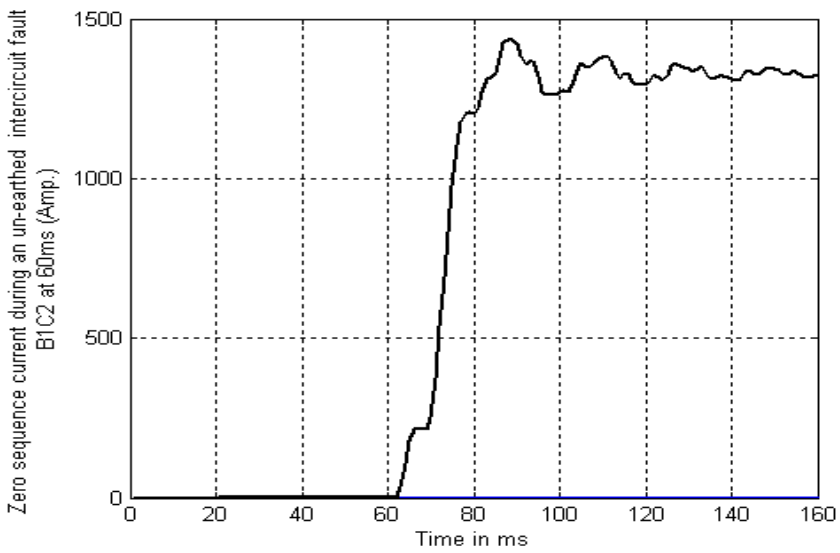

Figure 8. Zero sequence current waveform during un-earthed inter-circuit fault.
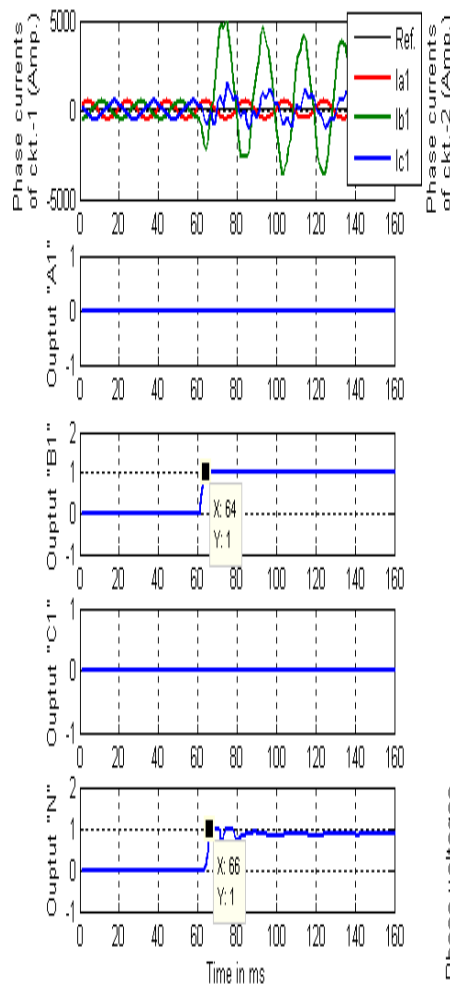
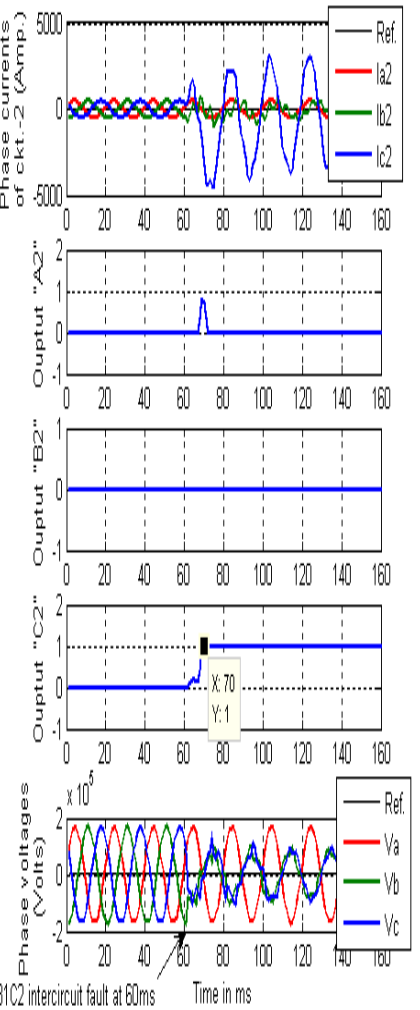

Figure 9. (a)
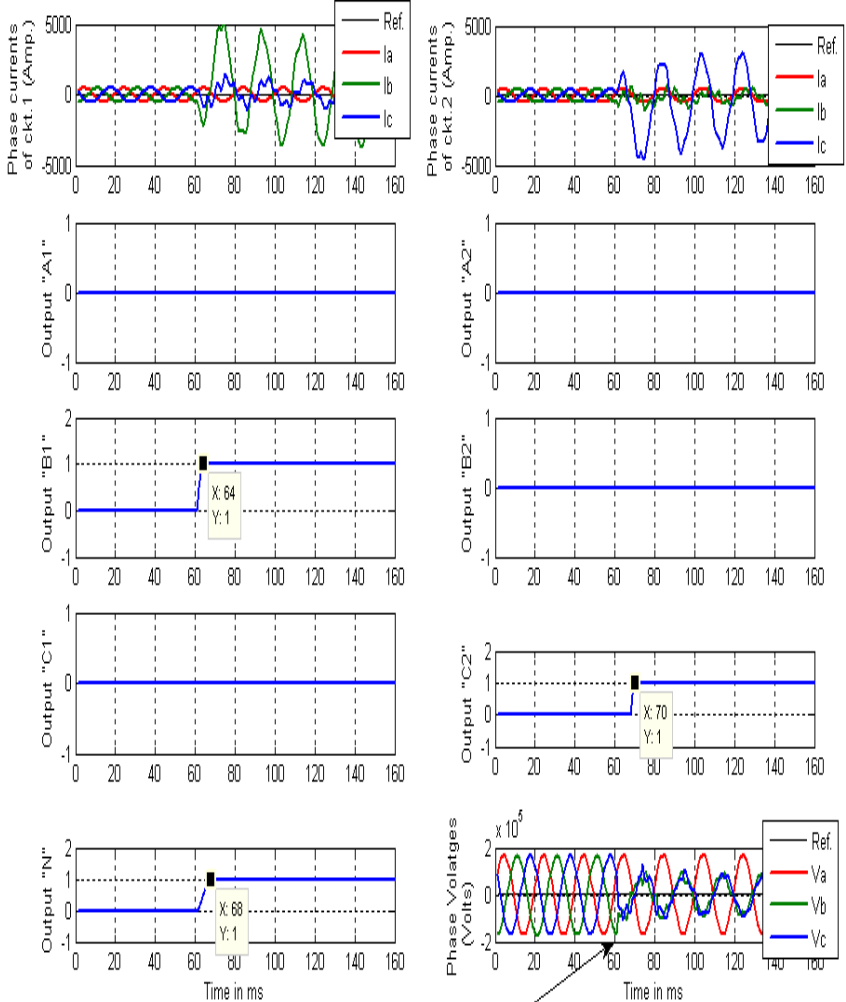

Figure 9. (b)

Figure 9. (a) and (b) Test results of single and modular ANN based fault detector/classifier for un-earthed inter-circuit fault respectively.

5.3 Test Results of three phase fault during single circuit operation of double circuit line: The conventional distance relays overreach when both circuits are in service and under-reach if one of the circuits is out of service and earthed at either end (Jongepier and van der Sluis, 1994.). The performance of single and modular ANN based fault detector and classifier during fault in ckt-2 when ckt-1 is out of service and grounded is investigated as shown in Fig.10. For example, ckt-1 opened and grounded and three phase fault in ckt-2 "A2B2C2" fault at $50 \mathrm{~km}$ from SS-1 end at $60 \mathrm{~ms}\left(\Phi_{\mathrm{i}}=0^{\circ}\right)$ with $\mathrm{R}_{\mathrm{f}}=0 \Omega, \delta_{\mathrm{s}}=45^{\circ}$ is created. Test results of single and modular ANN based fault detector and classifier are shown in Fig. 11 (a) and (b). From the test result of single ANN based fault detector and classifier shown in Fig. 11(a), the outputs A2, B2, C2 have fluctuation immediately after inception of fault and are constantly high after one cycle time and also neutral " $\mathrm{N}$ " output is high for half cycle time after the onset or inception of fault, thereafter it lowers down to zero value and other outputs are low. 
The outputs of modular ANN based fault detector and classifier as shown in Fig. 11(b); for three phase fault "A2B2C2" in corresponding phases are high within one cycle time and all other outputs are low. Thus, it correctly detects and classifies the three phase fault within one cycle time.

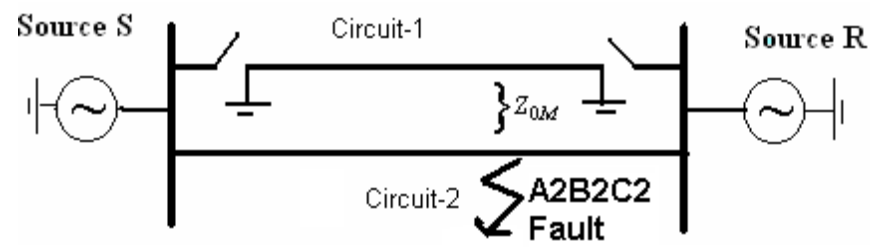

Figure 10. Double circuit line with ckt.-1 out of service; opened and grounded and fault in ckt.-2.

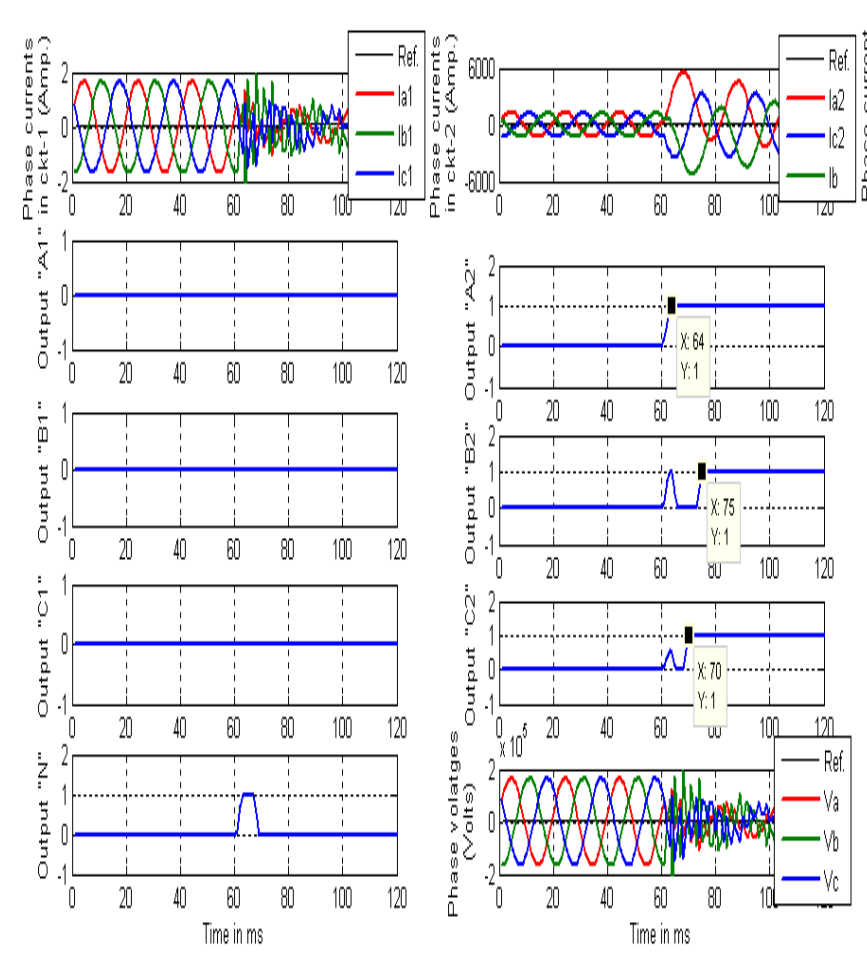

Figure 11. (a)
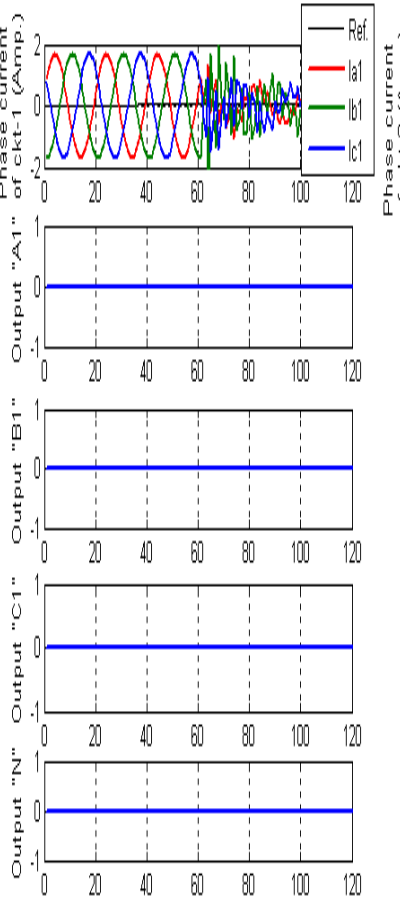

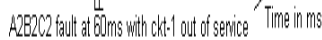

Figure 11. (b)

Figure 11. (a) and (b) Test results of single and modular ANN based fault detector/classifier during single circuit operation with fault in healthy circuit respectively.

5.4 Test Results with variation in pre-fault power flow angle $\left(\delta_{s}\right)$ : During training of ANN, the pre-fault power flow angle $\delta_{\mathrm{s}}$ is taken as $45^{\circ}$ to consider the condition of power flow near to its maximum capacity. However the proposed modular ANN based fault detector and classifier has been tested with variation in the pre-fault power flow angle $\delta_{\mathrm{s}}=25^{\circ}, 30^{\circ}, 35^{\circ}, 45^{\circ}$ etc. The convention distance relaying scheme mal-operates during power swings. Fig. 12 shows the test results of modular ANN based fault detector and classifier for "A1B1C1" fault in circuit- 1 with pre-fault power flow angle $\delta_{\mathrm{s}}=25^{\circ}$. Fault location is $50 \mathrm{KM}$ from the source "SS-1" and has occurred at $60 \mathrm{~ms}\left(\Phi_{\mathrm{i}}=0^{\circ}\right)$ with $\mathrm{R}_{\mathrm{f}}=0 \Omega$. The outputs of modular ANN based detector and classifier during no-fault condition upto $60 \mathrm{~ms}$ are low and the outputs becomes high in corresponding phases A1, B1 and C1 and other outputs are low at $62 \mathrm{~ms}$ i.e. within quarter cycle from the inception of fault as shown in the Fig. 12. Fig. 13 shows another test result for a "B1C1N" fault in circuit-1 with pre-fault power flow angle $\delta_{\mathrm{s}}=30^{\circ}$. Fault location is $65 \mathrm{KM}$ from the source "SS-1" and has occurred at $62.5 \mathrm{~ms}\left(\Phi_{\mathrm{i}}=45^{\circ}\right)$ with $\mathrm{R}_{\mathrm{f}}=0 \Omega$. The result shows that the fault is detected and classified correctly within one cycle time. 

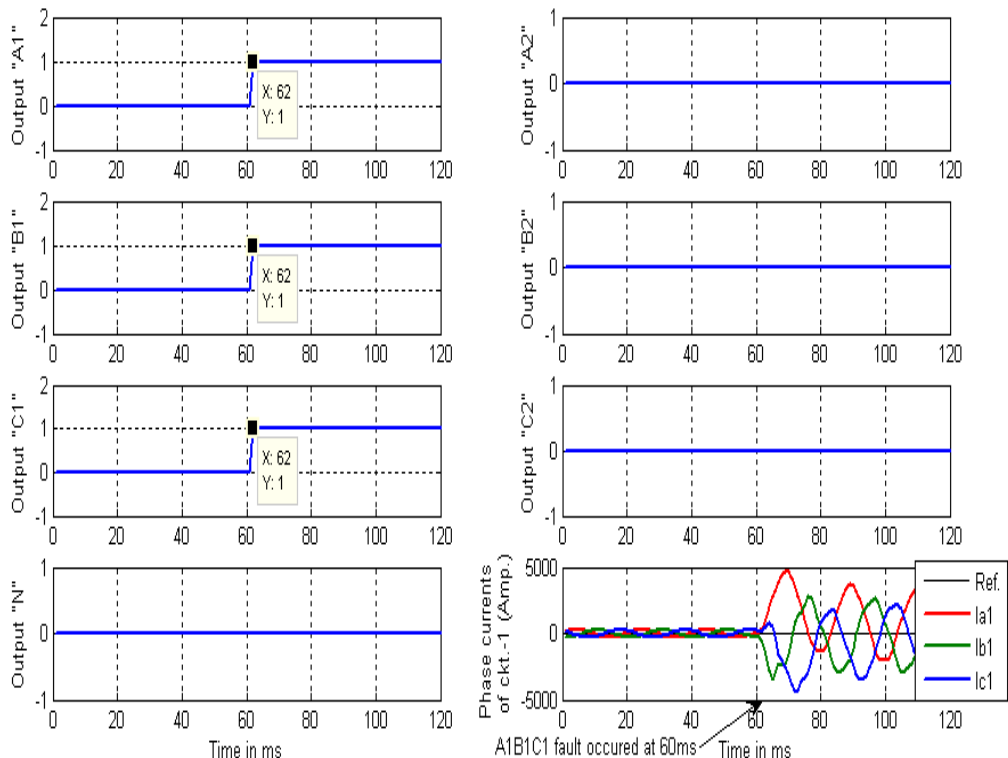

Fig. 12 Test result of modular ANN based fault detector and classifier for a three phase fault in ckt.-1 "A1B1C1" fault at $\Phi_{\mathrm{i}}=0^{\circ}$ (inception time $60 \mathrm{~ms}$ ), $50 \mathrm{KM}, \delta_{\mathrm{s}}=25^{\circ}$.
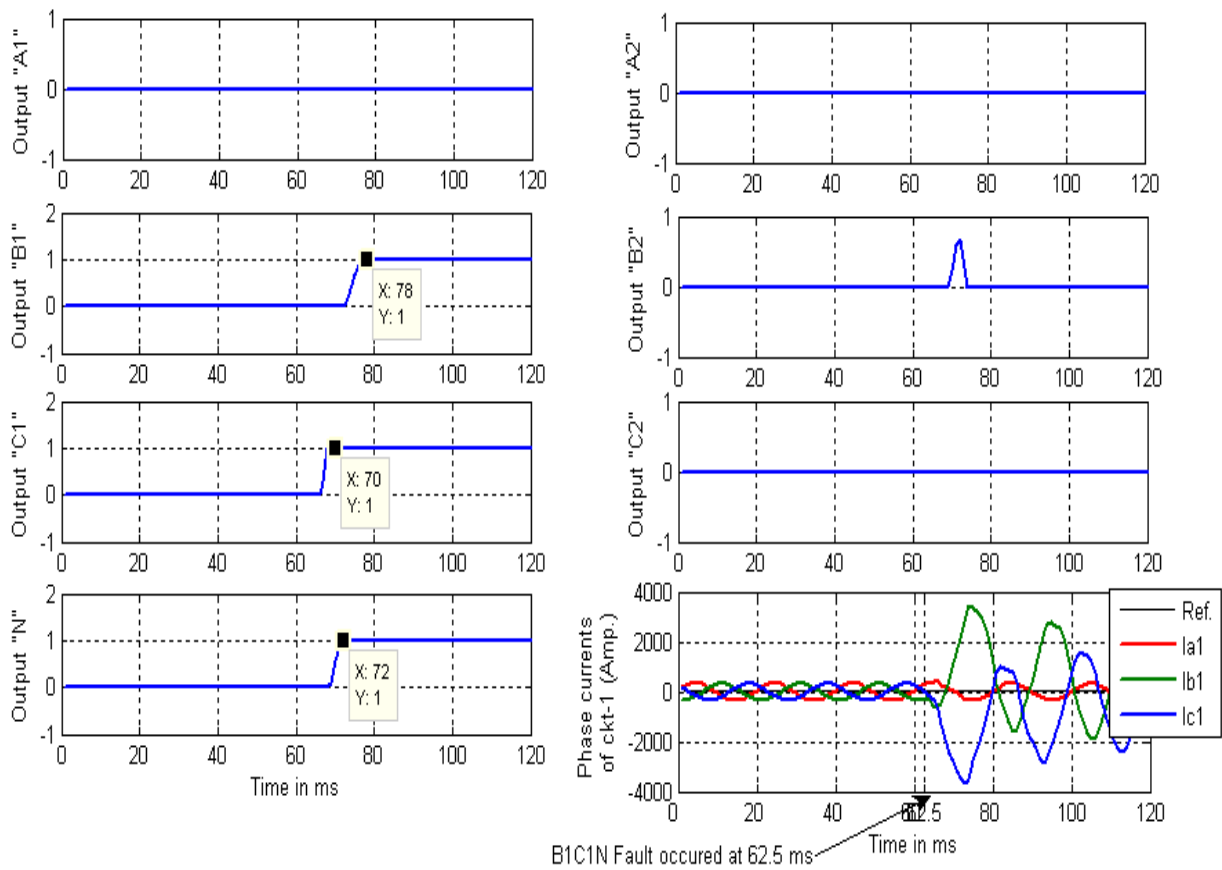

Fig. 13 Test result modular ANN based fault detector and classifier for "B1C1N" fault at $\Phi_{\mathrm{i}}=45^{\circ}$ (inception time $62.5 \mathrm{~ms}$ ) at 65 $\mathrm{KM}$ with $\mathrm{R}_{\mathrm{f}}=0 \Omega$, and $\delta_{\mathrm{s}}=30^{\circ}$.

\section{Conclusion}

Single and modular ANN modules were developed for detection and classification of all the ten types of faults in double circuit transmission line. The complexity of the all possible type of faults, namely LG faults (A1N, A2N, B1N, B2N, C1N \& C2N), LL faults (A1B1, A2B2, B1C1, B2C2, C1A1 \& C2A2), LLG faults (A1B1N, A2B2N, B1C1N, B2C2N, C1A1N \& C2A1N) and LLL faults (A1B1C1 \& A2B2C2), cross country faults, intercircuit faults, variations in fault locations (0-95\%), fault resistances $(0-100$ $\Omega$ ), fault inception angles $\left(0-360^{\circ}\right)$, source strengths, pre-fault power flow angles, mutual coupling effects and remote end in-feed 
are considered.

The test results of single ANN based fault detection and classification module shows that it gives correct results for single phase to ground and double phase to ground faults i.e. faults involving ground only. However, it has the limitation that it misclassifies the phase to phase and three phase faults as double phase to ground and three phase to ground faults respectively for one cycle period after the onset of fault. Since the relays are installed in the three phases and not in neutral, therefore in the event of fault, the corresponding phase relays must operate. Thus, it is not a serious drawback of single ANN based fault detector and classifier as it will not result in any serious maloperation of relays. Further, due to large number of training data set, training speed in single ANN based fault detector and classifier is very slow, and memory requirement is large. Thus, it is concluded that single ANN based fault detector and classifier has the disadvantage of complexity, large training sets and time, slow learning capability and larger errors. In modular approach, four different ANN modules for fault detection and classification according to the type of faults (LG, LL, LLG, and LLL) have been developed, tested and validated.

The comparison of the test results of single and modular approach has been presented in this paper. The modular ANN based test results are very encouraging and confirm the suitability of the technique for protection of double circuit transmission line. The proposed technique can be applied as an alternative protection scheme or a supplement to existing schemes. In practice the technique could thus be employed as a starter to switch in an optimum measuring algorithm in transmission line digital protection employing numeric techniques. It can also act as back up in the absence of communication link.

\section{Nomenclature}

ANN:- Artificial neural network

$\mathrm{L}_{\mathrm{f}}$ : Fault location/distance to fault in $\mathrm{km}$

$\delta_{\mathrm{s}}$ : pre-fault power flow angle in ${ }^{\circ}$

$\Phi_{\mathrm{i}}$ : Fault inception angle in ${ }^{\circ}$

$\mathrm{R}_{\mathrm{f}}$ : Fault resistance in ohms

$V_{a f}:$ Fundamental component of voltage of 'a' phase

$V_{b f}:$ Fundamental component of voltage of ' $b$ ' phase

$V_{c f}:$ Fundamental component of voltage of 'c' phase

$I_{a 1 f}$ : Fundamental component of voltage of 'a' phase of circuit-1

$I_{b 1 f}$ : Fundamental component of voltage of ' $b$ ' phase of circuit-1

$I_{c 1 f}$ : Fundamental component of voltage of 'c' phase of circuit-1

$I_{a 2 f}$ : Fundamental component of voltage of 'a' phase of circuit-2

$I_{b 2 f}$ : Fundamental component of voltage of ' $\mathrm{b}$ ' phase of circuit-2

$I_{c 2 f}$ : Fundamental component of voltage of 'c' phase of circuit-2

\section{References}

Agrasar M., Uriondo F., and J. R. Hernández, 1998. Evaluation of uncertainties in double lines distance relaying A global sight, IEEE Trans. Power Del., Vol. 12, No. 4, pp. 1033-1039.

Agrasar M., Uriondo F., Hernandez J. R., and Alvarez R., 1997. A useful methodology for analyzing distance relays performance during simple and inter-circuit faults in multi-circuit lines, IEEE Trans. Power Delivery, Vol. 12, No. 4, pp. 1465-1471.

Agarwal R.K., Xuan Q.Y., Dunn R.W., Johns A.T. and Bennett A., 1999. A novel fault classification technique of double circuit lines based on a combined unsupervised/supervised neural network, IEEE transactions on Power Delivery, Vol.14, No. 4, pp. 1250-1256.

Awasthi I., Ahmed A., 2012, Protection of transmission lines using artificial neural network, International Journal of Advanced Research in Computer Science and Software Engineering, Vol. 2, No. 7, pp. 70-73.

Babu K.V., Tripathy M. and Singh A.K., Recent techniques used in transmission line protection: a review, International Journal of Engineering, Science and Technology, Vol. 3, No. 3, 2011, pp. 1-8.

Bhalja B.R. and Maheswari R.P., 2007. High resistance faults on two terminal parallel transmission line: Analysis, simulation studies, and an adaptive distance relaying scheme, IEEE Trans. on Power Delivery, Vol. 22, No.2, pp. 801-812.

Bouthiba T., 2004. Fault location in EHV transmission lines using artificial neural networks, Int. J. Appl. Math. Comput. Sci., Vol. 14, No. 1, 69-78.

Caneloi dos Santos R., Cesar Senger E.C., 2011. Transmission lines distance protection using artificial neural networks, International Journal of Electrical Power \& Energy Systems, Vol. 33, No. 3, pp. 721-730. 
Coury D. V. and Jorge D.C., 1998. Artificial neural network approach to distance protection of transmission lines, IEEE Trans. Power Delivery, Vol. 13, No. 1, pp. 102-108.

Dash P.K., Pradhan A.K. and Panda G., 2001. Application of minimal radial basis function neural network to distance protection, IEEE Trans. on Power Delivery, Vol. 16, No.1, pp. 68-74.

Dalstain T., and Kulicke B., 1995. Neural network-approach to fault classification for high speed protective relaying, IEEE Trans. on Power Delivery, Vol. 10, No. 2, pp. 1002-1011.

Haykin S., 2003, Neural Network: A Comprehensive Foundation, Printice Hall of India, New Delhi, Second Edition.

Hagan M.T. and Menhaj M.B., 1994. Training feedforward networks with the Marquardt algorithm, IEEE Trans. on Neural Networks, Vol. 5, No. 6, pp. 989-993.

Jongepier A. G. and van der Sluis L., 1994. Adaptive distance protection of a double-circuit line, IEEE Trans. Power Delivery, Vol. 9, No. 3, pp. 1289-1297..

Kamel T.S., Moustafa-Hassan M.A., 2010. Adaptive Neuro fuzzy interface system for classification in the transmission lines. OJEEE, Vol. 2, No.1.

Khaparde S.A., Warke N. and Agarwal S.H.. 1996. An adaptive approach in distance protection using an artificial neural network, International Journal of Electric Power Systems Research, Vol. 37, No. 1, pp- 39-46.

Koley E., Yadav A. and Thoke A.S. 2012. Six phase to ground fault detection and classification of transmission line using ANN. International Journal of Computer Applications, Vol. 41, No. 4, pp. 6-10.

Lin W.M., Yang C.D., Lin J.H. and Tsay M.T., 2001. A fault classification method by RBF neural network with OLS learning procedure, IEEE Trans. on Power Delivery, Vol. 16, No. 4, pp. 473-477.

Mahanty R.N. and Gupta P.B.D. 2004. Application of RBF neural network to fault classification and location in transmission lines, IEE Proc-Gen. Trans. Distr. Vol. 151, No. 2, pp. 201-212.

Martins L.S., Martins J.F., Piers V.F. and Alegria C.M., 2005. A neural space vector fault location for parallel double-circuit distribution lines, Electrical Power and Energy Systems Journal, Vol. 27, pp- 225-231.

Mazon A.J., Zamora I., Minambres J. F., Zorrozua M.A., Barandiaran J.J. and Sagastabeitia K., 2000. A new approach to fault location in two-terminal transmission lines using artificial neural networks, International Journal of Electric Power Systems Research, Vol. 56, pp-261-266.

Protection of Double Circuit Transmission Lines (PDCTL), 2012, http://www.pacw.org/white_papers/protection/

transmission_line/protection_of_double_circuit_transmission_lines/complete_article/1.htm

Purushothama G.K., Narendranath A.U., Thukaram D. and Parthasarathy K., 2001, ANN applications in fault locators, Electrical Power and Energy Systems Journal, Vol. 23, pp. 491-506.

Reddy M.J. and Mohanta D.K., 2007. A wavelet-fuzzy combined approach for classification and location of transmission line faults, Electrical Power and Energy Systems, Vol.29, No.1, pp.669-678.

Salat R. and Osowski S., 2004. Accurate fault location in the power transmission line using support vector machine approach, IEEE Trans. Power Delivery, Vol.19, No.2., pp.979-986.

Samantaray S.R. and Dash P.K., 2008. Transmission line distance relaying using machine intelligence technique, IET Gener. Transm. Distrib., Vol.2, No.1, pp.53-61.

Samantaray S.R., 2009. Decision tree-based fault zone identification and fault classification in flexible AC transmission-based transmission line, IET GTD, Vol. 3, No. 5, pp. 425-436.

Samantaray S.R., Dash P.K. and Panda G., 2006. Fault classification and location using HS transform and radial basis functions neural network, International Journal of Electrical Power System Research, Vol. 76, pp. 897-905.

Sanaye-Pasand M. and Malik O.P. 1998. High speed transmission system directional protection using Elman network, IEEE Trans. Power Delivery, Vol. 13, No. 4, pp. 1040-1045.

Sanaye-Pasand M., Khorashadi-Zadeh H., 2003. Transmission Line Fault Detection and Phase Selection using ANN, International Conference on Power Systems Transients - IPST 2003 in New Orleans, USA

Sanaye-Pasand M. and Khorashadi-Zadeh H., 2006. An extended ANN-based high speed accurate distance protection algorithm, International Journal of Electrical Power \& Energy Systems, Vol.28, No.6, pp-387-395.

Skok S., Marusic A., Tesnjak S. and Pevik L., 2002. Double-circuit line adaptive protection based on Kohonen neural network considering different operation and switching modes Power Engineering 2002 Large Engineering Systems Conference on LESCOPE, Vol.2, pp- $153-157$.

Spoor D. J. and Zhu, J. 2005. Intercircuit faults and distance relaying of dual-circuit lines IEEE Trans. Power Delivery, Vol. 20, No. 3, pp. 1846-1852.

Vankayala V.S. and Rao N.D., 1993. Artificial NNs and their application to power systems -a bibliographical survey, International Journal of Electrical Power System Research, Vo1.28, pp.67-79.

Venkatesan R. and Balamurugan B., 2001. A real-time hardware fault detector using an artificial neural network for distance protection, IEEE Transactions on Power Delivery, Vol. 16, No. 1, pp. 75-82.

Wang H. and Keerthipala W.W.L., 1998. Fuzzy-neuro approach to fault classification for transmission line protection, IEEE Trans. Power Delivery, Vol. 13, No.4, pp. 1093-1104. 
Warlyani P., Jain A., Thoke A.S. and Patel R.N., 2011, Fault classification and faulty section identification in teed transmission circuits using ANN, International Journal of Computer and Electrical Engineering, Vol.3, No.6, pp. 807-811.

Xuan Q.Y, Song Y .H. and Johns A.T., 1996. Performance of an adaptive protection scheme for series compensated EHV transmission lines using neural networks, International Journal of Electrical Power System Research, Vol. 136, No 1, pp 57-66.

.Xuan Q.Y, Aggarwal R.K., Johns A.T., Dunn R.W. and Bennett A., 1998. A neural network based protection technique for combined 275kV/400kV double circuit transmission lines, Neurocomputing, Vol. 23, pp 59-70.

\section{Biographical notes}

Anamika Yadav received her B.E. in Electrical Engineering from RGPV Bhopal in year 2002. She acquired her M.Tech in Integrated Power Systems from V.N.I.T., Nagpur, India in 2006. She worked as Assistant Engineer in the Chhattisgarh State Electricity Board, Raipur, C.G, India from July, 2004 to March, 2009. Since March 2009 she is working as Assistant Professor in Department of Electrical Engineering, National Institute of Technology, Raipur, C.G., India. Her research interest is in application of Soft computing techniques to Power System protection. Dr. Yadav is a member of The IET, with designatory title M.I.E.T., member of IEEE and Associate member of I.E. India. She has published more than 36 papers in various referred international, national journals and conferences. She is the sole author of a book entitled "ANN Based Fault Detection, Classification and Distance Location" published by LAMBERT Academic Publishing (LAP) $\mathrm{GmbH} \&$ Co. KG, ISBN No. 978-3-8465-4563-8. She is the reviewer of International journal on Generation, Transmission \& Distribution of I.E.T, UK, International journal on Electric Power Components and Systems Taylor and Francis, IEEE Transaction on Power Delivery, International Journal of Engineering, Science and Technology and Journal of Electrical and Electronics Engineering Research, Academic journals.

Received May 2012

Accepted June 2012

Final acceptance in revised form August 2012 